\section{THU0256 RHEUMATIC DISEASES ARE THE MOST COMMON CAUSE OF LONG TERM DISABILITY (LTD) COMPARED TO OTHER MAJOR DISEASE GROUPS (MDG) IN URBAN, SUBURBAN AND RURAL GREEK POPULATION}

A Andrianakos, S Aslanides, F Christogiannis, P Trontzas, G Karanikolas, D Karamitsos, P Krachtis, C Voudouris, G Kaziolas, K Pantelidou, E Tavaniotou, A Georgountzos. Hellenic Foundation for Rheumatological Research, Hellenic Foundation for Rheumatological Research, Athens, Greece

\subsection{6/annrheumdis-2001.800}

\section{Background}

Objectives To assess the prevalence of LTD caused by RD or any other MDG was one of the aims of a population-based epidemiological study of RD in Greece (ESORDIG study).

Methods All adult (>18 years) residents of two urban (U), one suburban (SU) and four rural (R) communities of Greece were included in this 3 year (1996-1999) study (8,547 subjects), along with 2,100 randomly selected subjects of $1 \mathrm{SU}(1: 3)$ and $1 \mathrm{R}$ (1:2) communities. Sixteen rheumatologists performed the study and 8,740 adults were included (out of a total of 10,647, response rate $82.1 \%$ ). The study included a detailed interview based on a standardised questionnaire. LTD was defined as ?the limitation of occupational or any other activities because of a long-term physical or mental disorder or health problem, compared to other people of the same age in good health?.

Established classification criteria (ECC) were used for the diagnosis of RD, while, for the purpose of the study, such criteria were set for RD without ECC.

Results From 2,393 subjects (out of 8,740, 27.4\%) suffering from RD, $394(16.5 \%)$ also had LTD. Thus, the prevalence of LTD caused by RD was $4.5 \%$ in the general population (GP), being higher in women $(6.2 \%)$ than in men $(2.8 \%, \mathrm{p}<0.0005)$. LTD prevalence increased with age, being $11.6 \%$ in subjects $>68$ years, while no significant differences were observed between the three $(\mathrm{U}, \mathrm{SU}, \mathrm{R})$ communities. The total prevalence of LTD from any cause was $9.8 \%$ in the GP and RD were the most common cause, being responsible of $46.2 \%$ of all LTD, followed by cardiovascular diseases (CVD, 22.7\%). Analysis for sex, age and community revealed that RD were always the leading cause of LTD, but in men aged $>58$ years, CVD were first (41.3\%), with RD second (25.4\%).

Conclusion The results of this study show that $\mathrm{RD}$, compared with other MDG, are the leading cause of LTD in the general population. Since LTD is the major contributing factor for the total indirect cost of all MDG, these findings concerning RD appear to be of considerable value in planning rheumatology research and health care services.

\section{THU0257 RHEUMATIC DISEASES AS A CAUSE OF SHORT TERM DISABILITY (STD) COMPARED TO OTHER MAJOR DISEASE GROUPS (MDG) IN URBAN, SUBURBAN AND RURAL GREEK POPULATION}

A Andrianakos, S Aslanides, P Georgountzos, E Tavaniotou, C Antoniadis, P Trontzas, L Kontelis, P Dandis, C Voudouris, E Vafiadou, Z Nikolia, E Kaskani. Hellenic Foundation for Rheumatological Research, Hellenic Foundation for Rheumatological Research, Athens, Greece

10.1136/annrheumdis-2001.801

Background
Objectives To assess the prevalence of STD caused by RD or any other MDG was one of the aims of a population-based epidemiological study of RD in Greece (ESORDIG study).

Methods This 3 year (1996-1999) study included all adult (>18 years) residents of two urban (U), one suburban (SU) and four rural (R) communities of Greece (8,547 subjects), along with 2,100 randomly selected subjects of $1 \mathrm{SU}$ (1:3) and $1 \mathrm{R}(1: 2)$ communities. Sixteen rheumatologists performed the study and 8,740 adults were included (out of a total of 10,647, response rate $82.1 \%$ ). The study included a detailed interview based on a standardised questionnaire. Short term disability (STD) was defined as ?staying in bed or restriction of usual physical activities for one day or more because of a physical or mental disorder or health problem during the last 2 weeks before the interview?. Established classification criteria (ECC) were used for the diagnosis of RD, while, for the purpose of the study, such criteria were set for RD without ECC.

Results The overall prevalence of STD caused by RD was $2.8 \%$ in the general population (GP) and was significantly higher in women $(3.5 \%)$ than in men $(2 \%, p<0.0005)$. Significant differences were observed between age groups: $1.5 \%$ in the $19-45$ year-group, compared with $4 \%$ in the $>45$ year-group ( $p<$ $0.0005)$, while there were no differences between communities (U 2.9\%, SU 2.3\%, R 3\%). The total prevalence of STD from all causes was $10.9 \%$ in GP; RD were the most common cause of STD (25.2\%), followed by respiratory diseases (ReD, 21.2\%), cardiovascular diseases (CVD, 17.1\%) and gastrointestinal diseases (GI, 8.2\%). Analysis for age and sex showed that RD were always the most common cause of STD, with the exception of the 19-28 year-group, where ReD were first (31\%), followed by $\mathrm{RD}(12.1 \%)$ and the $>68$ year-group, where CVD were first (32.8\%), followed by ReD (18.3\%) and RD (17.6\%).

Conclusion The findings of this study show that, compared with other MDG, RD are the major cause of STD in the adult GP, mainly in the middle age groups.

\section{THU0258 MELOXICAM DOES NOT INCREASE THE RISK OF ACUTE MYOCARDIAL INFARCTION, CONGESTIVE HEART FAILURE, OEDEMA OR HYPERTENSION COMPARED TO NSAIDS: RESULTS FROM A POOLED ANALYSIS OF 27,039 PATIENTS}

G Singh. Medicine/Immunology and Rheumatology, Stanford University Medical Center, Palo Alto, USA

\subsection{6/annrheumdis-2001.802}

Background Meloxicam is a novel NSAID that has been widely used in $>100$ countries with $>40$ million prescriptions over the last 6 years. Meloxicam has been shown in numerous clinical trials to be effective, and to have lower rates of gastrointestinal adverse events than other NSAIDs such as diclofenac, piroxicam and naproxen. However, the renal and cardiovascular toxicity of meloxicam has not been extensively studied before. This is an important clinical issue because recent studies have raised considerable concern about cardiovascular and renal safety profile of some new Cox-2 selective NSAIDs.

Objectives To document the risk of acute myocardial infarction, congestive heart failure, oedema and hypertension in patients taking 7.5-30 mg doses of meloxicam, and traditional NSAIDs (diclofenac 100-150 mg, naproxen 500-750 mg, piroxicam 20 $\mathrm{mg}$ ) in a pooled analysis of 27,039 patients. 